\title{
Integrated Fire Management Concepts for promoting and stabilizing resilient ecosystems
}

\author{
Daniel Almeida Rocha ${ }^{1 *}$
}

\begin{abstract}
${ }^{1}$ ONG Brigada 1, Municipal Parks and Zoobotany Foundation, Minas Gerais, Brazil.
*Contact email: presidente@ brigada1.org.br/ rocha.biologia@ gmail.com
\end{abstract}

\begin{abstract}
Fire is a transforming and modeling element of natural environments, used by humans as a management tool for thousands of years. Its controlled use is indicated, and has been defended by specialists, for the borders of protected areas with native vegetation under anthropic pressure. The implement of fire management preventive actions, in opposition to the expensive efforts to eliminate it in preserved areas, corroborates to minimize the disastrous consequences of eventual fire. This is because a managed plant biomass is reduced and forms a mosaic of fuel discontinuity which, being mainly invasive alien species, alters fire regimes, combinations and ecosystem functions. Among different types of burning, controlled and prescribed burns stand out. These are characterized by the planned, monitored and controlled use of fire, carried out for conservation, research or management purposes, with predefined objectives in the Integrated Fire Management (IFM) plan. Its actions are related to the use of prescribed or controlled burning and forest fire prevention and control, with the purpose of reducing particulate matter and gas emissions, conserving biodiversity and minimizing the severity of future fires. This paper aims to analyze an experience of restoration of native forests of Serra do Rola Moça State Park (SRMSP) through natural regeneration and also the use of forest enrichment techniques, comparing the cost benefit of the methods. In order to achieve this experience, the IFM will be implemented in areas with high presence of invasive exotic grasses, defined the width of the native forest expansion bands and prescribed burns around this vegetation that will be selected via satellite imaging and conference in field of phytogeographic characteristics. In addition, there will be collection and dispersal of seeds from native vegetation, production and planting of seedlings and installation of ornithofauna attraction perches as forest enrichment techniques. Thus, from the results and records obtained, it is proposed to define a schedule for the continued action of those involved, seeking to enable greater resilience of these native forests of SRMSP and, thus, strengthen their natural regeneration.
\end{abstract}

Keywords: integrated fire management, prescribed burning, forest enrichment, forest restoration, natural regeneration. 